\title{
FORMULATION AND IN VITRO EVALUATION OF EZETIMIBE RAPIDMELTS
}

\author{
T NEELIMA RANI*, Y INDIRA MUZIB
}

Department of Pharmaceutics, Institute of Pharmaceutical Technology, Sri Padmavathi Mahila Visvavidyalayam (Women's University), Tirupati, Andhra Pradesh, India. Email: neelimarani.tumma@gmail.com

Received: 12 December 2019, Revised and Accepted: 12 March 2020

ABSTRACT

Objective: The main objective of the present research was formulation and evaluation of ezetimibe rapidmelts.

Methods: As ezetimibe comes under Class II drug, solubility of the drug should be increased before formulation. For that solid dispersions were prepared with $\beta$-CD and PVP K-30 using coevaporation and kneading method. Among those solid dispersions prepared with $\beta$-CD (1:1.5) using coevaporation method has given better drug entrapment values compared to other solid dispersions. Those solid dispersions were formulated as rapidmelts using direct compression. In direct compression method, rapidmelts were prepared using superdisintegrants such as crospovidone, croscarmellose sodium, and starch 1500. Those are evaluated for both pre-compression and post-compression parameters. Rapidmelts of ezetimibe were prepared using sublimation method with subliming agents camphor, urea, and ammonium bicarbonate. The concentrations of subliming agents were found to be $2.5,5.0$, and $7.5 \%$.

Results: Rapidmelts prepared using direct compression and sublimation methods were evaluated for weight variation, hardness, friability, \% drug content, and disintegration time. The best formulation was subjected to stability testing for 6 months at $25^{\circ} \mathrm{C} / 60 \% \mathrm{RH}$ and $40^{\circ} \mathrm{C} / 75 \% \mathrm{RH}$. All the prepared formulations compiled with the pharmacopeial limits. In all the formulations, results suggest that E12 formulation has given the best results.

Conclusion: From the result, it was concluded that rapidmelts prepared using sublimation method which has given better result than direct compression method. That final formulation was further evaluated for in vivo studies using rabbits.

Keywords: Ezetimibe, $\beta$-Cyclodextrin, PEG 6000, PEG 4000, Coevaporation, Kneading, Direct compression, Sublimation, Superdisintegrants, Subliming agents.

(C) 2020 The Authors. Published by Innovare Academic Sciences Pvt Ltd. This is an open access article under the CC BY license (http://creativecommons. org/licenses/by/4. 0/) DOI: http://dx.doi.org/10.22159/ajpcr.2020.v13i5.36620

\section{INTRODUCTION}

Oral route of administration is one among the foremost convenient route for drug administration. As per USFDA, rapidmelts were defined as "A solid dosage form containing a medicinal substance or active ingredient which disintegrates rapidly when placed upon the tongue within a matter of seconds" [1]. After disintegration, the drug solution is often partially or completely absorbed by the sublingual blood vessels and bypasses first-pass metabolism by the liver or be absorbed from the gastrointestinal tract after swallowing. Prescription rapidmelt products initially were developed to beat the problem in swallowing among pediatric and geriatric populations who have difficulty in swallowing conventional tablets and capsules [2].

Nowadays, rapidmelts are going to be more widely available as overthe-counter products for the management of the many conditions such as lowering cholesterol, heart problems, allergies, and cold. The presence of a highly porous surface with in the tablet matrix is that one among the key factors for the rapid disintegration of oral disintegrative tablet. Many methods were reported for solubility and dissolution enhancement of poorly soluble drug such as micronization, complexation, solid dispersions, and kneading method. Solid dispersions are a way that depends on melting or dissolution process to disperse one or more active ingredient during in a carrier or matrix with in the solid state. This ensures increased drug wettability and reduction of particle aggregation and hence increased drug dissolution [3].

Pediatric and geriatric patients will face many difficulties in swallowing or chewing pharmaceutical dosage forms for oral administration. Tablets that rapidly dissolve on contact with buccal cavity could present an answer to those problems then there is an increased interest fastdissolving dosage forms for buccal, sublingual, and oral administration.
Fast-dissolving/disintegrating tablets are ideal fit to those patients as they immediately release the active drug when placed on the tongue by rapid disintegration [4]. Hence, with in the present investigation, rapidmelts of ezetimibe were prepared.

The drug ezetimibe was widely utilized in the treatment of hyperlipidemia. It acts as a cholesterol absorption inhibitor. Hyperlipidemia drugs are mainly want to reduce cholesterol levels in patients in danger of disorder. Ezetimibe is practically insoluble in water and crystalline compound. For oral absorption, dissolution is thus the rate limiting step. To reinforce the bioavailability improvement in solubility and dissolution rate are essential.

As ezetimibe comes under BCS Class II drug, solid dispersions of ezetimibe were prepared using different polymers in several ratios using different techniques to reinforce the solubility of the drug. Solid dispersions were formulated as rapidmelts using different superdisintegrants using direct compression method. To enhance the porosity, volatile substances like subliming agents are often utilized in tableting process, which sublimated from the formed tablet. Ezetimibe rapidmelts were prepared using direct compression and sublimation techniques.

\section{MATERIALS AND METHODS}

\section{Materials}

Ezetimibe was obtained as a present sample from MSN Laboratories Ltd., Hyderabad. $\beta$-cyclodextrin, polyethylene glycol 6000, polyethylene glycol 4000, crospovidone, croscarmellose sodium, starch 1500, magnesium stearate, Aerosil, microcrystalline cellulose, camphor, urea, ammonium bicarbonate, talc, aspartame, and mannitol were kindly supplied by BMR Pharma and Chemicals. All the other solvents used were analytical grade. 


\section{Methods}

Calibration curve for ezetimibe

For the preparation of ezetimibe stock solution. For the stock solution, ezetimibe $10 \mathrm{mg}$ was taken and dissolved in few $\mathrm{ml}$ of methanol. The stock solutions were diluted with methanol to organize the concentrations 5 , $10,15,20$, and $25 \mu \mathrm{g} / \mathrm{ml}$ of ezetimibe. They were analyzed by UV-visible spectrophotometer at $233 \mathrm{~nm}$ using methanol as blank. A calibration curve was plotted against concentration and absorbance.

\section{Preparation of solid dispersions}

Solvent evaporation method

For the preparation of solid dispersions, drug and polymers were mixed in a mortar with ratios $(1: 0.5,1: 1$, and 1:1.5). Ethanol was added in proportion wise with constant and continuous stirring until the mixture was completely dissolved. Ethanol was evaporated under constant stirring and resultant solid dispersions were collected (Table 1).

\section{Kneading method}

In a mortar, $50 \%$ of solvent was taken there to add calculated amount of polymer and is triturated to urge slurry-like consistency. Then, the drug was incorporated, remaining solvent was added, and trituration is sustained for $1 \mathrm{~h}$, air-dried at $25^{\circ} \mathrm{C}$ for $48 \mathrm{~h}$, and therefore, the resulting dried product was pulverized and skilled mesh sieve (Table 2).

\section{Evaluation of solid dispersions}

Drug entrapment efficiency

Each solid dispersion about $10 \mathrm{mg}$ was weighed and placed in glass Stoppard tubes and redispersed in $3 \mathrm{ml}$ water. The dispersion was then lysed with $1 \mathrm{ml}$ chloroform to permit for complete release for entrapped drug. Complete extraction of the drug was done by shaking the tubes for $6 \mathrm{~h}$ in water bath shaker at $37^{\circ} \mathrm{C}$. The centrifugation of the samples was done at $6000 \mathrm{rpm}$ for $5 \mathrm{~min}$ and then allowed to face for complete separation of the two phases. The collected aqueous solutions were analyzed for determining the drug concentration as previously described (Table 3). Drug concentration was also used for determining $\%$ encapsulation efficiency consistent with the subsequent formula.

\section{$\%$ Encapsulation efficiency $=($ Actual drug loading $/$ Theoretical drug} loading) $\times 100$

Drug entrapment for solid dispersions

Among both the methods, cosolvent evaporation was found to be entrapped good compared to kneading method.

\section{Preparation of ezetimibe rapidmelts}

Ezetimibe rapidmelts were prepared using direct compression and sublimation methods

\section{Direct compression method}

In direct compression method supported entrapment values $69.6 \mathrm{mg}$ of solid dispersions which was taken equivalent to $10 \mathrm{mg}$ of drug ezetimibe. Formulation of rapidmelts was done using superdisintegrants croscarmellose sodium, crospovidone, and starch 1500 in concentrations of 2,4 , and $6 \%$. All the ingredients were skilled through the mesh. Then, all the ingredients were mixed in geometric order, and therefore, the tablets were compressed with $8 \mathrm{~mm}$ size round punch (Table 4 ).

\section{Sublimation method}

Rapidmelts of ezetimibe were prepared using subliming agents such as camphor, urea, and ammonium bicarbonate in concentrations of 2.5, 5, and $7.5 \%$ from the ultimate tablet weight. Accurately weighed amounts of ingredients were thoroughly mixed and compressed into $200 \mathrm{mg}$ tablets using single punch machine of $8 \mathrm{~mm}$ round punch and die set. Ezetimibe tablets were then placed in an oven at $40^{\circ} \mathrm{C}$ till a continuing weight is obtained (Table 5).

\section{Evaluation of ezetimibe rapidmelts}

Pre-compression parameters

The various characteristics of blends to be conducted before compression are as follows:

\section{Angle of repose}

The fixed funnel method was used to decide the angle of repose. The funnel height was adjusted in such how that the tip of the funnel just touched the apex of the heap of the granules. The granules were allowed to flow onto the funnel freely onto the surface. The peak and diameter of the granular cone was measured and angle of repose was calculated.

Bulk density and tapped density

An appropriate amount of powder from each formulation was taken and was introduced into the $10 \mathrm{ml}$ measuring cylinder. After measuring initial volume, the cylinder was allowed to fall into its own weight onto a tough surface from a height of $2.5 \mathrm{~cm}$ at $2 \mathrm{~s}$ intervals. The tapping of the measuring cylinder was continued until there is no further change in volume which was noted.

\section{Bulk density $=$ Weight of the powder/Bulk volume of the powder}

Tapped density $=$ Weight of the powder/Tapped volume of the powder

Carr's index: The Carr's index was used to measure the compressibility index of the powder blend.

\section{Carr's index $=($ Tapped density - Bulk density $/$ Tapped density $) \times 100$}

Hausner's ratio: Using the bulk and tapped density, Hausner's ratio of ezetimibe blend powder formulation was calculated and it's expressed as:

Hausner's ratio = Tapped density/bulk density.

Table 1: Preparation of ezetimibe solid dispersions using solvent evaporation method

\begin{tabular}{lllllll}
\hline Excipients & $\mathbf{1 : 0 . 5}$ (EZE1) & $\mathbf{1 : 1}$ (EZE2) & $\mathbf{1 : 1 . 5}$ (EZE3) & $\mathbf{1 : 0 . 5}$ (EZE4) & 1:1 (EZE5) & 1:1.5 (EZE6) \\
\hline $\begin{array}{l}\text { Drug }(\mathrm{mg}) \\
\begin{array}{l}\beta \\
\text { PEGclodextrin }(\mathrm{mg})\end{array}\end{array}$ & 500 & 500 & 500 & 500 & 500 & 500 \\
\begin{tabular}{l} 
Water and ethanol \\
\hline
\end{tabular} & 500 & 750 & 250 & 500 & 750 \\
\hline
\end{tabular}

Table 2: Preparation of ezetimibe solid dispersions using kneading method

\begin{tabular}{|c|c|c|c|c|c|c|}
\hline Excipients & 1:0.5 (EZE7) & 1:1 (EZE8) & 1:1.5 (EZE9) & 1:0.5 (EZE10) & 1:1 (EZE11) & 1:1.5 (EZE12) \\
\hline Drug (mg) & 500 & 500 & 500 & 500 & 500 & 500 \\
\hline$\beta$-cyclodextrin (mg) & 250 & 500 & 750 & & & \\
\hline PEG 4000 (mg) & \multirow{2}{*}{\multicolumn{6}{|c|}{ Quantity sufficient for paste formation }} \\
\hline Water and ethanol (ml) & & & & & & \\
\hline
\end{tabular}


Post-compression parameters

Hardness

The typical breaking strength of tablets was decided by tablet hardness tester (Monsanto hardness tester). Ten tablets from each formula were tested for its hardness. The mean hardness $( \pm \mathrm{SD})$ of every formula was determined.

\section{Weight variation}

Weight variation test was administered to ensure the uniformity of tablets. From each formulation, 20 tablets were randomly selected and separately weighed. Their average weight was calculated.

\section{Friability}

Ten tablets from each batch were collected to the gauge evaluate the friability. The tablets were placed in the Roche friabilator and subjected to $25 \mathrm{rpm}$ for a period of $4 \mathrm{~min}$. Then, the tablets were dusted and once more reweighed. The percentage loss in weights was calculated and taken as a measure of friability.

\section{Wetting time}

Five circular tissue papers of $10 \mathrm{~cm}$ diameter were placed during Petri dish with a $10 \mathrm{~cm}$ diameter. A tablet was placed on the surface of tissue. The time required for water to reach the upper surface of the tablets was noted as the wetting time. The wetting time of the formulations was measured in seconds.

\section{In vitro disintegration time}

Disintegration test apparatus was used to measure the in vitro disintegration time. One tablet was placed in each of the six tubes of

Table 3: Drug entrapment efficiency values of ezetimibe solid dispersions

\begin{tabular}{llll}
\hline SD & Solvent evaporation method & SD & Kneading method \\
\hline EZE1 & 65.7 & EZE7 & 53.5 \\
EZE2 & 66.46 & EZE8 & 58.23 \\
EZE3 & 69.6 & EZE9 & 60.28 \\
EZE4 & 52.6 & EZE10 & 54.98 \\
EZE5 & 61.8 & EZE11 & 60.23 \\
EZE6 & 65.6 & EZE12 & 62.9 \\
\hline
\end{tabular}

the basket assembly of the disintegration apparatus and then disk was placed on to each tube. This assembly was then suspended during a $1 \mathrm{~L}$ beaker containing water with its temperature being maintained at $37 \pm 2^{\circ} \mathrm{C}$. The basket was then moved up and down through a distance of $5-6 \mathrm{~cm}$, at the frequency of $28-32$ cycles $/ \mathrm{min}$. The time required for the complete disintegration of the tablet was noted.

In vitro dissolution studies

The dissolution profiles of ezetimibe from rapidmelts were determined in a dissolution tester, apparatus II. All tests were conducted in $900 \mathrm{ml}$ phosphate buffer $\mathrm{pH} 7.0$ containing $0.5 \%$ SLS at a temperature of $37 \pm 0.5^{\circ} \mathrm{C}$ with a paddle rotation speed at $50 \mathrm{rpm}$. Samples were collected at specified time intervals $1,5,10,15,20,25,30,35,40,45$, and $50 \mathrm{~min}$. A $5 \mathrm{ml}$ of dissolution medium was replaced with an equal volume of medium to take care of a constant total volume. Samples were filtered through a $0.45 \mu \mathrm{m}$ Millipore filter and assayed for drug content spectrophotometrically at $233 \mathrm{~nm}$.

\section{Characterization}

Fourier transform infrared (FT-IR) studies

The concentration of the sample in $\mathrm{KBr}$ should be within the range of $0.2-1 \%$. The pellet is far thicker than a liquid film, hence, a lower concentration within the sample is required (Beer's law). The infrared IR beam is absorbed completely or scattered from the sample which ends up in very noisy spectra.

\section{Differential scanning calorimetry (DSC)}

DSC was used to evaluate drug-excipient compatibility. The endotherms of pure drug and optimized formulation were recorded separately. The DSC thermograms are obtained by a DSC (DSC 220C, Seiko, Japan) at a heating rate of $10^{\circ} \mathrm{C} / \mathrm{min}$ from 10 to $200^{\circ} \mathrm{C}$ with in the nitrogen atmosphere.

\section{Stability studies}

To review the steadiness of the rapidmelts, representative samples of the were packed in amber colored airtight glass containers and that they were stored in stability chambers maintained at $25^{\circ} \mathrm{C} / 60 \% \mathrm{RH}$ and $40^{\circ} \mathrm{C} / 75 \% \mathrm{RH}$. The physicochemical properties of those samples were analyzed at 0,3 , and 6 months. From the respective storage conditions at each time point, one formulation was taken out and subjected to content uniformity and dissolution rate studies.

Table 4: Composition of ezetimibe rapidmelts by direct compression method

\begin{tabular}{|c|c|c|c|c|c|c|c|c|c|}
\hline Compound name & E1 & E2 & E3 & E4 & E5 & E6 & E7 & E8 & E9 \\
\hline Equivalent solid dispersion (mg) & 69.6 & 69.6 & 69.6 & 69.6 & 69.6 & 69.6 & 69.6 & 69.6 & 69.6 \\
\hline $\mathrm{CP}(\mathrm{mg})$ & 4 & & & 8 & & & 12 & & \\
\hline $\operatorname{CCS}(\mathrm{mg})$ & & 4 & & & 8 & & & 12 & \\
\hline Starch 1500 (mg) & & & 4 & & & 8 & & & 12 \\
\hline Magnesium stearate (mg) & 3 & 3 & 3 & 3 & 3 & 3 & 3 & 3 & 3 \\
\hline Aerosil (mg) & 2 & 2 & 2 & 2 & 2 & 2 & 2 & 2 & 2 \\
\hline MCC (mg) & 121.4 & 121.4 & 121.4 & 117.4 & 117.4 & 117.4 & 113.4 & 113.4 & 113.4 \\
\hline
\end{tabular}

Table 5: Composition of ezetimibe rapidmelts by sublimation method

\begin{tabular}{|c|c|c|c|c|c|c|c|c|c|}
\hline Compound name & E10 & E11 & E12 & E13 & E14 & E15 & E16 & E17 & E18 \\
\hline Ezetimibe (mg) & 10 & 10 & 10 & 10 & 10 & 10 & 10 & 10 & 10 \\
\hline Camphor (mg) & 5 & 10 & 15 & & & & & & \\
\hline Urea (mg) & & & & 5 & 10 & 15 & & & \\
\hline Ammonium bicarbonate (mg) & & & & & & & 5 & 10 & 15 \\
\hline Crospovidone (mg) & 4 & 4 & 4 & 4 & 4 & 4 & 4 & 4 & 4 \\
\hline Aspartame (mg) & 2 & 2 & 2 & 2 & 2 & 2 & 2 & 2 & 2 \\
\hline Magnesium stearate (mg) & 2 & 2 & 2 & 2 & 2 & 2 & 2 & 2 & 2 \\
\hline Mannitol (mg) & 176 & 171 & 166 & 176 & 171 & 166 & 176 & 171 & 166 \\
\hline Total weight (mg) & 200 & 200 & 200 & 200 & 200 & 200 & 200 & 200 & 200 \\
\hline
\end{tabular}




\section{RESULTS AND DISCUSSION}

\section{Pre-compression parameters}

The values of angle of repose were found to be within the range of $25-30^{\circ} \mathrm{C}$ bulk densities and tapped densities of varied formulations were found to be within the range of $0.30-0.70\left(\mathrm{~g} / \mathrm{cm}^{2}\right)$. Carr's index was found to be within the range of $14-25 \%$. The Hausner's ratio was within the range of 1.15-1.35. From the result, it had been concluded that powder blends have good flow properties.

\section{Post-compression parameters}

Hardness of all the formulations was found to be within the range of $3-4.5 \mathrm{~kg} / \mathrm{cm}^{2}$. It indicated that each one of the formulations possesses sufficient mechanical strength. Weight variation was found to be in the range of IP limits. Rapid melts were evaluated for their \% friability using
Roche friabilator. The average $\%$ friability values were found to be $<1 \%$. It indicates good mechanical strength of the tablets. In vitro disintegration time of all the formulations was found to be in the range of 110-180 s. The results indicate that increasing concentration of superdisintegrants disintegration time of tablet was decreased. Disintegration time of the tablets was decreased with more concentration of subliming agents (camphor $7.5 \%$ ). All the formulations have shown disintegration time $<3 \mathrm{~min}$. Hence, these formulations are suitable for formulating rapidmelts. Drug content values for the all formulations were found to be within the IP standards (not $<95 \%$ and not more than 105\%) (Tables 6-11).

\section{In vitro drug release studies}

The values are shown in Tables 10 and 11. Formulations from E1 to E9 were prepared using superdisintegrants (CCS, CP, and SSG) by direct

Table 6: Pre-formulation parameters for ezetimibe rapidmelts by direct compression method

\begin{tabular}{|c|c|c|c|c|c|}
\hline Formulation code & Angle of repose $\left(^{\circ}\right)$ & Bulk density (mg/ml) & Tapped density (mg/ml) & Carr's index (\%) & Hausner's ratio \\
\hline E1 & $24.53 \pm 0.01$ & $0.61 \pm 0.01$ & $0.71 \pm 0.01$ & $16 \pm 0.01$ & $1.2 \pm 0.01$ \\
\hline E2 & $25.26 \pm 0.12$ & $0.61 \pm 0.11$ & $0.71 \pm 0.11$ & $14.0 \pm 0.15$ & $1.15 \pm 0.25$ \\
\hline E3 & $29.13 \pm 0.21$ & $0.59 \pm 0.02$ & $0.73 \pm 0.25$ & $24.01 \pm 0.1$ & $1.83 \pm 0.11$ \\
\hline $\mathrm{E} 4$ & $28.58 \pm 0.11$ & $0.61 \pm 0.2$ & $0.71 \pm 0.03$ & $14.10 \pm 0.10$ & $1.17 \pm 0.13$ \\
\hline E5 & $27.78 \pm 0.05$ & $0.6 \pm 0.01$ & $0.74 \pm 0.15$ & $18.32 \pm 0.10$ & $1.2 \pm 0.21$ \\
\hline E6 & $24.3 \pm 0.17$ & $0.58 \pm 0.11$ & $0.71 \pm 0.05$ & $22.13 \pm 0.02$ & $1.6 \pm 0.05$ \\
\hline E7 & $26.83 \pm 0.10$ & $0.6 \pm 0.15$ & $0.75 \pm 0.24$ & $19.32 \pm 0.05$ & $1.23 \pm 0.04$ \\
\hline E9 & $28.15 \pm 0.05$ & $0.62 \pm 0.04$ & $0.74 \pm 0.11$ & $16.26 \pm 0.20$ & $1.18 \pm 0.05$ \\
\hline
\end{tabular}

Table 7: Post-compression parameters for ezetimibe rapidmelts by direct compression method

\begin{tabular}{|c|c|c|c|c|c|c|}
\hline $\begin{array}{l}\text { Formulation } \\
\text { code }\end{array}$ & Hardness $\left(\mathrm{kg} / \mathrm{cm}^{2}\right)$ & Average weight (mg) & Drug content (\%) & Friability (\%) & Disintegration time (s) & Wetting time (s) \\
\hline E1 & $4.1 \pm 0.01$ & $198 \pm 0.01$ & $99.98 \pm 0.01$ & $0.7 \pm 0.01$ & $160 \pm 0.01$ & $44.2 \pm 2$ \\
\hline E2 & $3.5 \pm 0.01$ & $196.5 \pm 0.21$ & $101.32 \pm 0.11$ & $0.82 \pm 0.10$ & $168 \pm 0.05$ & $52.8 \pm 2$ \\
\hline E3 & $3.1 \pm 0.23$ & $199.3 \pm 015$ & $100.01 \pm 0.10$ & $0.65 \pm 0.05$ & $152 \pm 0.10$ & $58.4 \pm 6$ \\
\hline E4 & $4.3 \pm 0.15$ & $197.8 \pm 0.05$ & $102.32 \pm 0.20$ & $0.74 \pm 0.11$ & $163 \pm 0.12$ & $42.6 \pm 5$ \\
\hline E5 & $3.5 \pm 0.22$ & $198.5 \pm 0.25$ & $101 \pm 0.10$ & $0.56 \pm 0.05$ & $165 \pm 0.24$ & $40.6 \pm 1$ \\
\hline E6 & $3.3 \pm 0.34$ & $200.6 \pm 0.12$ & $102.4 \pm 0.05$ & $0.58 \pm 0.02$ & $159 \pm 0.10$ & $40.8 \pm 8$ \\
\hline E8 & $3.9 \pm 0.24$ & $196.4 \pm 0.01$ & $101 \pm 0.01$ & $0.5 \pm 0.11$ & $172 \pm 0.06$ & $30.8 \pm 3$ \\
\hline E9 & $4.0 \pm 0.04$ & $195.5 \pm 0.11$ & $100.5 \pm 0.05$ & $0.45 \pm 0.12$ & $150 \pm 0.08$ & $32.4 \pm 1$ \\
\hline
\end{tabular}

Table 8: Pre-compression parameters for ezetimibe rapidmelts using sublimation method

\begin{tabular}{|c|c|c|c|c|c|}
\hline Formulation code & Angle of repose $\left({ }^{\circ}\right)$ & Bulk density (mg/ml) & $\mathrm{TD}(\mathrm{mg} / \mathrm{ml})$ & Carr's index (\%) & Hausner's ratio \\
\hline E10 & $25.3 \pm 0.01$ & $0.33 \pm 0.21$ & $0.42 \pm 0.11$ & $21.38 \pm 0.01$ & $1.20 \pm 0.01$ \\
\hline E11 & $26.5 \pm 0.12$ & $0.36 \pm 0.02$ & $0.41 \pm 0.01$ & $22.12 \pm 0.21$ & $1.35 \pm 0.12$ \\
\hline E12 & $24.2 \pm 0.25$ & $0.31 \pm 0.06$ & $0.46 \pm 0.21$ & $17.53 \pm 0.32$ & $1.28 \pm 0.05$ \\
\hline E13 & $27.13 \pm 0.12$ & $0.35 \pm 0.05$ & $0.52 \pm 0.04$ & $20.41 \pm 0.11$ & $1.19 \pm 0.22$ \\
\hline E14 & $26.4 \pm 0.11$ & $0.32 \pm 0.15$ & $0.46 \pm 0.03$ & $25.18 \pm 0.15$ & $1.26 \pm 0.14$ \\
\hline E15 & $28.33 \pm 0.32$ & $0.39 \pm 0.12$ & $0.43 \pm 0.01$ & $19.25 \pm 0.21$ & $1.34 \pm 0.22$ \\
\hline E16 & $25.65 \pm 0.15$ & $0.41 \pm 0.22$ & $0.49 \pm 0.11$ & $16.93 \pm 0.24$ & $1.20 \pm 0.21$ \\
\hline E18 & $26.25 \pm 0.01$ & $0.34 \pm 0.10$ & $0.45 \pm 0.25$ & $24.58 \pm 0.11$ & $1.34 \pm 0.11$ \\
\hline
\end{tabular}

Table 9: Post-compression parameters for ezetimibe rapidmelts using sublimation method

\begin{tabular}{|c|c|c|c|c|c|c|}
\hline $\begin{array}{l}\text { Formulation } \\
\text { code }\end{array}$ & Hardness $\left(\mathrm{kg} / \mathrm{cm}^{2}\right)$ & Average weight (mg) & Drug content (\%) & Friability (\%) & $\begin{array}{l}\text { In vitro disintegration } \\
\text { time (s) }\end{array}$ & Wetting time (s) \\
\hline E10 & $4.08 \pm 0.05$ & $200.1 \pm 0.01$ & $100.1 \pm 0.05$ & $0.49 \pm 0.05$ & $120 \pm 0.01$ & $36.2 \pm 2$ \\
\hline E11 & $3.15 \pm 0.02$ & $199.8 \pm 0.12$ & $98.39 \pm 0.12$ & $0.45 \pm 0.06$ & $135 \pm 0.12$ & $34.8 \pm 4$ \\
\hline E12 & $3.8 \pm 0.12$ & $198.12 \pm 0.03$ & $100.25 \pm 0.01$ & $0.53 \pm 0.01$ & $115 \pm 0.01$ & $26.4 \pm 1$ \\
\hline E13 & $3.80 \pm 0.11$ & $201.50 \pm 0.05$ & $101 \pm 0.05$ & $0.62 \pm 0.12$ & $125 \pm 0.15$ & $36.8 \pm 5$ \\
\hline E14 & $3.9 \pm 0.14$ & $200 \pm 0.06$ & $100 \pm 0.21$ & $0.65 \pm 0.13$ & $129 \pm 0.21$ & $40.2 \pm 7$ \\
\hline E15 & $4.10 \pm 0.10$ & $197.5 \pm 0.15$ & $99.93 \pm 0.11$ & $0.59 \pm 0.24$ & $149 \pm 0.10$ & $40.8 \pm 6$ \\
\hline E17 & $3.4 \pm 0.05$ & $200 \pm 0.15$ & $100.30 \pm 0.10$ & $0.42 \pm 0.11$ & $127 \pm 0.02$ & $36.4 \pm 3$ \\
\hline E18 & $4 \pm 0.04$ & $199 \pm 0.10$ & $98.3 \pm 0.11$ & $0.52 \pm 0.10$ & $146 \pm 0.12$ & $34.8 \pm 1$ \\
\hline
\end{tabular}


Table 10: Cumulative \% drug release for formulations prepared using direct compression method

\begin{tabular}{|c|c|c|c|c|c|c|c|c|c|}
\hline Time (min) & E1 & E2 & E3 & E4 & E5 & E6 & E7 & E8 & E9 \\
\hline 0 & 0 & 0 & 0 & 0 & 0 & 0 & 0 & 0 & 0 \\
\hline 5 & $31.02 \pm 0.02$ & $20.13 \pm 0.11$ & $9.39 \pm 0.10$ & $17.3 \pm 0.10$ & $18.12 \pm 0.02$ & $15.26 \pm 0.010 .21$ & $40.12 \pm 0.05$ & $18.12 \pm 0.10$ & $16.09 \pm 0.01$ \\
\hline 10 & $48.5 \pm 0.25$ & $31.52 \pm 0.20$ & $22.83 \pm 0.05$ & $40.12 \pm 0.05$ & $49.05 \pm 0.10$ & $50.12 \pm 0.05$ & $69.88 \pm 0.10$ & $40.6 \pm 0.15$ & $32.69 \pm 0.05$ \\
\hline 15 & $65.83 \pm 0.01$ & $48.92 \pm 0.10$ & $30.12 \pm 0.02$ & $55.8 \pm 0.01$ & $65.23 \pm 0.10$ & $61.68 \pm 0.06$ & $85.32 \pm 0.11$ & $56.12 \pm 0.20$ & $61.83 \pm 0.20$ \\
\hline 20 & $79.12 \pm 0.11$ & $60.64 \pm 0.01$ & $36.39 \pm 0.01$ & $63.35 \pm 0.20$ & $73.42 \pm 0.05$ & $68.39 \pm 0.10$ & $100 \pm 0.11$ & $65.85 \pm 0.14$ & $86.25 \pm 0.10$ \\
\hline 25 & $87 \pm 0.05$ & $74.24 \pm 0.02$ & $51.02 \pm 0.21$ & $76.21 \pm 0.11$ & $80.78 \pm 0.11$ & $76.41 \pm 0.12$ & & $80.5 \pm 0.20$ & $100.1 \pm 0.11$ \\
\hline 30 & $91.22 \pm 0.21$ & $85.13 \pm 0.06$ & $67.58 \pm 0.20$ & $88.01 \pm 0.01$ & $88.24 \pm 0.12$ & $88.89 \pm 0.15$ & & $99.89 \pm 0.05$ & \\
\hline 40 & & $101 \pm 0.10$ & $82.63 \pm 0.01$ & & $101.65 \pm 0.25$ & & & & \\
\hline 45 & & & $90.99 \pm 0.20$ & & & & & & \\
\hline 50 & & & $100 \pm 0.25$ & & & & & & \\
\hline
\end{tabular}

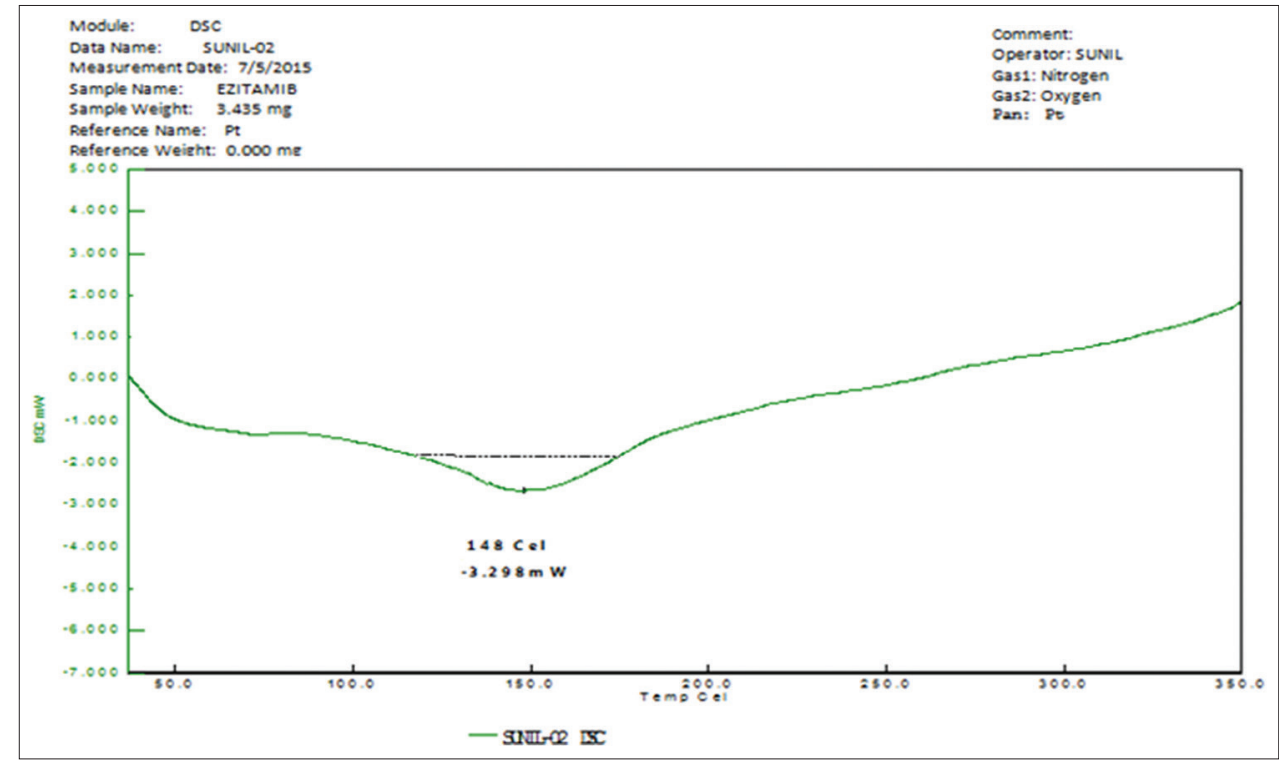

Fig. 1: Differential scanning calorimetry thermogram for ezetimibe pure drug

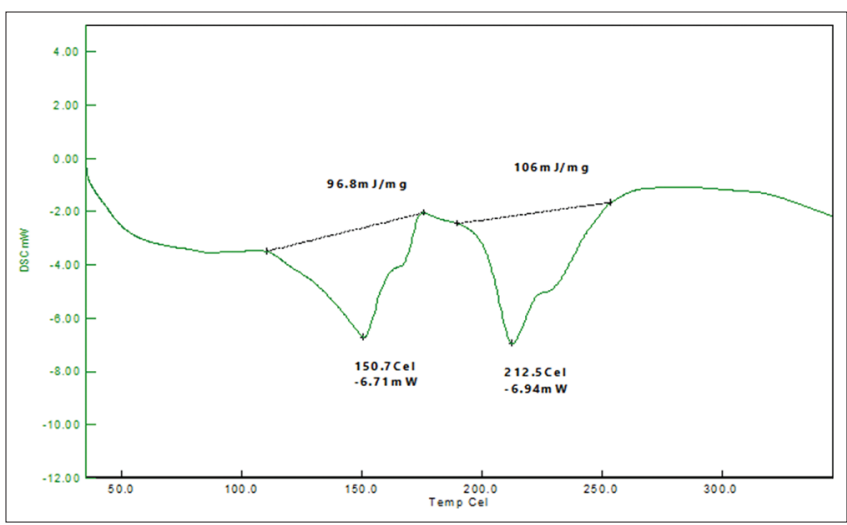

Fig. 2: Differential scanning calorimetry thermogram for ezetimibe optimized formulation

compression method. E10-E18 were prepared using subliming agents (camphor, urea, and ammonium bicarbonate). In direct compression method, superdisintegrants will act by swelling of the drug and it leads to faster disintegration and dissolution. In sublimation method, subliming agents will act by increasing the porosity of drug results in faster wetting and dissolution and bioavailability. Among all the formulations, E12 (camphor 7.5\%) has given better dissolution compared to all the formulations. Hence, E12 formulation was selected as optimized as $100 \%$ drug release in 5 min.

\section{Stability studies}

Hence, based on evaluation parameters and drug release profiles, E12 was selected as optimized and subjected to stability studies and stored at $25^{\circ} \mathrm{C} / 60 \% \mathrm{RH}$ and $40^{\circ} \mathrm{C} / 75 \% \mathrm{RH}$. The samples were withdrawn at 0 , 3 , and 6 months, and therefore, the ezetimibe rapidmelts were found to be stable. The amounts of ezetimibe (\%) in the rapidmelts stirred under conditions consistent with ICH guidelines are given in Table 12. The steadiness of the tablets indicated that there are no significant changes observed throughout the study. From the stability studies result, we can say that formulation has good stability.

\section{Characterization}

DSC analysis

DSC thermograms for pure drug and optimized formulation are got within the Figs. 1 and 2. The DSC thermogram of ezetimibe rapidmelts exhibiting a pointy endothermic peak at $150^{\circ} \mathrm{C}$ corresponding to the melting point of the drug ezetimibe, indicating that there was no change in its characteristics, this means that the drug polymer compatibility. DSC thermograms indicate that there were no interactions between drug and excipients.

\section{FTIR studies}

FTIR spectrum of ezetimibe exhibited peaks at $3676 \mathrm{~cm}^{-1}$ for alcohol $\mathrm{O}-\mathrm{H}$ stretch, $1593 \mathrm{~cm}^{-1}$ for alcohol $\mathrm{C}=0$ stretching, and $756 \mathrm{~cm}^{-1}$ for aromatic $\mathrm{C}=\mathrm{H}$ bending. The same peaks of the drug were observed within the FTIR spectra of the rapidmelts, thereby ruling the absence of drug-polymer interaction from the obtained results. Hence, further 
Table 11: Cumulative \% drug release for formulations prepared using sublimation method

\begin{tabular}{|c|c|c|c|c|c|c|c|c|c|}
\hline Time (min) & E10 & E11 & E12 & E13 & E14 & E15 & E16 & E17 & E18 \\
\hline 0 & 0 & 0 & 0 & 0 & 0 & 0 & 0 & 0 & 0 \\
\hline 1 & $20.11 \pm 0.01$ & $18.02 \pm 0.01$ & $25.03 \pm 0.11$ & $4.12 \pm 0.01$ & $5.01 \pm 0.01$ & $9.01 \pm 0.05$ & $3.02 \pm 0.01$ & $5.02 \pm 0.05$ & $5.02 \pm 0.05$ \\
\hline 2 & $31.12 \pm 0.25$ & $29.01 \pm 0.11$ & $45.05 \pm 0.21$ & $8.03 \pm 0.10$ & $7.02 \pm 0.10$ & $18.02 \pm 0.10$ & $8.04 \pm 0.05$ & $9.03 \pm 0.10$ & $10.01 \pm 0.20$ \\
\hline 3 & $45.21 \pm 0.11$ & $43.52 \pm 0.10$ & $72.12 \pm 0.15$ & $10.15 \pm 0.12$ & $9.04 \pm 0.05$ & $25.05 \pm 0.20$ & $10.02 \pm 0.02$ & $11.05 \pm 0.20$ & $15.01 \pm 0.25$ \\
\hline 4 & $75.12 \pm 015$ & $73.11 \pm 0.15$ & $89.01 \pm 0.14$ & $15.09 \pm 0.20$ & $14.09 \pm 0.10$ & $32.15 \pm 0.22$ & $13.05 \pm 0.10$ & $16.09 \pm 0.11$ & $22.12 \pm 0.10$ \\
\hline 5 & $98.73 \pm 0.21$ & $96.3 \pm 0.21$ & $99.89 \pm 0.20$ & $19.12 \pm 0.25$ & $18.12 \pm 0.11$ & $50.12 \pm 0.10$ & $16.09 \pm 0.15$ & $22.83 \pm 0.05$ & $30.12 \pm 0.06$ \\
\hline 10 & & & & $60.12 \pm 0.10$ & $45.05 \pm 0.02$ & $75.15 \pm 0.15$ & $40.06 \pm 0.20$ & $51.02 \pm 0.20$ & $67.58 \pm 0.05$ \\
\hline 20 & & & & $95.32 \pm 0.10$ & $85.13 \pm 0.22$ & & $88.80 \pm 0.21$ & $98.73 \pm 0.05$ & $99.59 \pm 0.10$ \\
\hline 25 & & & & & $97.16 \pm 0.25$ & & $96.32 \pm 0.11$ & & \\
\hline
\end{tabular}

Table 12: Stability studies

\begin{tabular}{|c|c|c|c|c|c|}
\hline \multirow{2}{*}{$\begin{array}{l}\text { Time (min) } \\
\text { o months }\end{array}$} & \multirow[t]{2}{*}{$\%$ dissolution rate } & \multicolumn{2}{|c|}{$\begin{array}{l}25^{\circ} \mathrm{C} / 60 \% \mathrm{RH} \\
\text { dissolution rate after storage) \% }\end{array}$} & \multicolumn{2}{|c|}{$\begin{array}{l}40^{\circ} \mathrm{C} / 75 \% \mathrm{RH} \\
\text { (dissolution rate after storage) } \%\end{array}$} \\
\hline & & 3 months & 6 months & 3 months & 6 months \\
\hline 0 & 0 & 0 & 0 & 0 & 0 \\
\hline 1 & $25.03 \pm 0.11$ & $25.05 \pm 0.15$ & $25.07 \pm 0.01$ & $25.01 \pm 0.06$ & $25.05 \pm 0.05$ \\
\hline 2 & $45.05 \pm 0.21$ & $46.01 \pm 0.07$ & $45.10 \pm 0.05$ & $45.01 \pm 0.20$ & $45.05 \pm 0.04$ \\
\hline 3 & $72.12 \pm 0.15$ & $72.15 \pm 0.08$ & $72.10 \pm 0.10$ & $72.10 \pm 0.13$ & $72.11 \pm 0.14$ \\
\hline 5 & $99.89 \pm 0.20$ & $99.87 \pm 0.16$ & $99.85 \pm 0.08$ & $99.88 \pm 0.21$ & $99.89 \pm 0.16$ \\
\hline
\end{tabular}

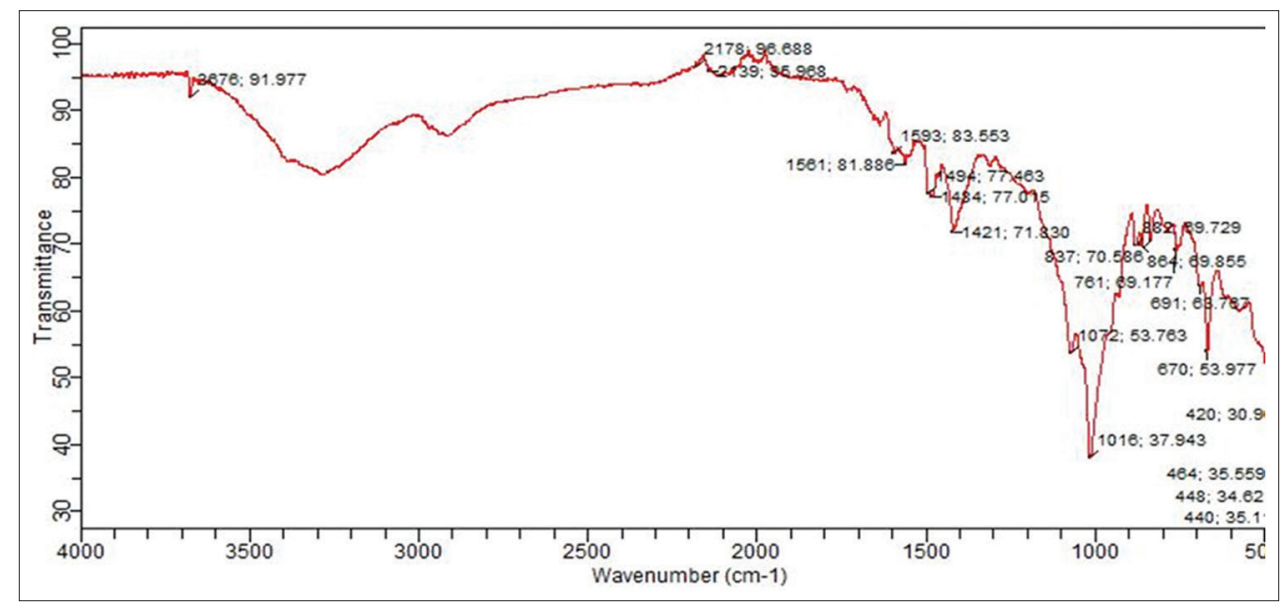

Fig. 3: Fourier transform infrared spectrum for ezetimibe optimum formulation

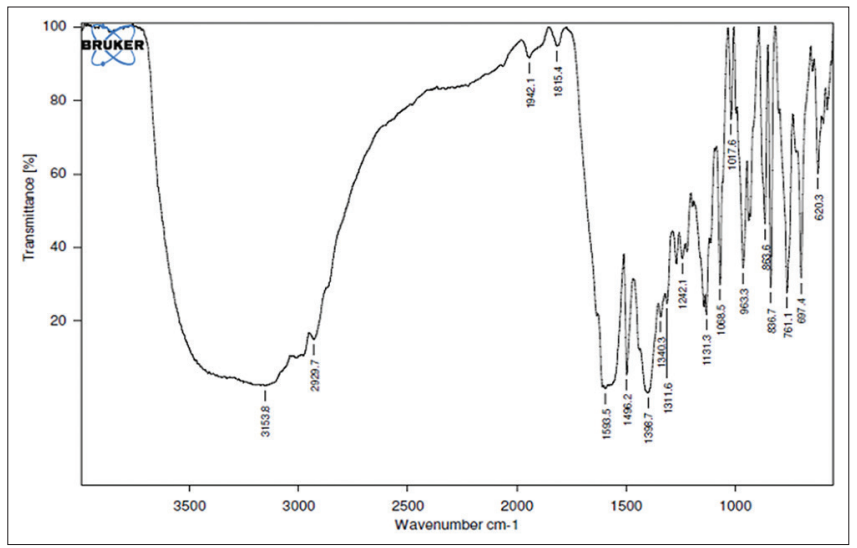

Fig. 4: Fourier transform infrared spectrum for ezetimibe pure drug studies were performed based on these results. FTIR spectroscopy analysis was performed to pure drug and optimized formulation and presented in Figs. 3 and 4.

\section{CONCLUSION}

Rapidmelts are also known as oral disintegrating tablets (or) fastdissolving tablets. These are mainly intended to be placed in the oral cavity where they dispersed before being swallowed. This is the promising dosage form for the use in pediatrics and geriatrics. The rapidmelts will provide accurate dosing and show good chemical and physical stability with lower doses. The present study was done on rapidmelts of ezetimibe using direct compression and sublimation methods. As ezetimibe comes under BCS Class II, solubility of ezetimibe was enhanced by preparing solid dispersions. The prepared solid dispersions were formulated as rapidmelts using direct compression method. In the sublimation method, rapidmelts were prepared using subliming agents. The prepared blends were evaluated for 
pre-compression studies such as bulk density, tapped density, Carr's index, Hausner's ratio, and angle of repose. They were found to be within limits. After completion of pre-compression studies, required powder blend was weighed and compressed using tablet compression machine. They were kept for post-compression studies such as weight variation, hardness, friability, in vitro disintegration, and dissolution studies. From dissolution studies, rapidmelts prepared using camphor (7.5\%) which has given maximum drug release within $5 \mathrm{~min}$. Hence, it was concluded that rapidmelts prepared using sublimation method which has given better result than direct compression method. Hence, sublimation method would be an effective method for the preparation of rapidmelts.

\section{ACKNOWLEDGMENT}

This article does not contain any studies with human and animal subjects performed by any of authors. Authors wish to thank the Sri Padmavathi Mahila University for providing necessary facilities to carry out research work.

\section{AUTHORS' CONTRIBUTIONS}

We here with to submit a manuscript entitled: "Formulation and In vitro evaluation of ezetimibe rapidmelts" author by Neelimarani. $\mathrm{T}$ and Indira Muzib. Y for the consideration for the journal as a research paper in the journal Asian Journal of Pharmaceutical and Clinical Research. Neelima Rani Tumma analyzed the laboratory work, analyzed the data, and wrote the manuscript. Both the authors read and approved the manuscript. All authors are the guarantors.

\section{CONFLICTS OF INTEREST}

The authors declare that there are no conflicts of interest for the publication of the paper. Authors have not received any funding.

\section{REFERENCES}

1. Rani TN, Muzib YI. Rapid melts: A review. Int J Pharm Chem Sci 2014;3:118-30

2. Velmurugan S, Vinushitha S. Oral disintegrating tablets: An overview. Int J Chem Pharm Sci 2010;1:1-12.

3. Patidar K, kshirsagar MD, Saini V, Joshi PB, Soni M. Solid dispersion technology: A boon for poorly soluble drugs. Indian J Drug Deliv 2011;3:83-90.

4. Elbary AA, Ali AA, Aboud H. Enhanced dissolution of meloxicam from orodispersible tablets prepared by different methods. Bull Fac Pharm 2012;50:89-97.

5. Mahesh A, Shastri N, Sadanandam M. Development of taste masked fast disintegrating films of levocetirizine dihydrochloride for oral use. Curr Drug Deliv 2010;7:21-7.

6. Guptaa S, Hasnainb MS, Agarwala SS. Formulation and evaluation of oral disintegrating tablets of itopride hydrochloride using ion exchange resins as drug carrier. Asian J Pharm Sci 2012;7:207-18

7. Raheem A, Singh R, Hiremath A, Nayak NS, Kamath KS. Formulation and comparative evaluation of ondansetron hydrochloride mouth dissolving tablets in India. Int J Pharm Pharm Sci 2019;11:57-64.

8. Agiba $\mathrm{AM}$, Eldin $\mathrm{AB}$. Insights into formulation technologies and novel strategies for the design of orally disintegrating dosage forms: A comprehensive industrial review. Int J Pharm Pharm Sci 2019;11:8-20. 